\title{
PENGARUH KUANTITAS, KEMAMPUAN KOMUNIKASI INTERPERSONAL, DAN PERILAKU ALTRUISME ANGGOTA KELOMPOK TERHADAP SOCIAL LOAFING DALAM PROSES DISKUSI KELOMPOK DI FAKULTAS KEDOKTERAN UNIVERSITAS UDAYANA

\author{
Putu Yoga Sukma Pratama dan Ni Made Swasti Wulanyani \\ Program Studi Psikologi, Fakultas Kedokteran, Universitas Udayana \\ yoganeutron69@gmail.com
}

\begin{abstract}
Abstrak
Social loafing merupakan kecenderungan individu untuk memberikan usaha minimal terhadap pencapaian kelompok. Adanya Social loafing dapat merugikan anggota kelompok lain, karena tidak seimbangnya kontribusi yang diberikan individu dan hasil yang diperoleh individu tersebut. Diperlukan pertimbangan tepat agar Social loafing dalam kelompok dapat ditekan kemunculannya. Faktor yang perlu dipertimbangkan tersebut diantaranya ukuran kelompok, komunikasi interpersonal, dan perilaku altruisme. Penelitian ini merupakan penelitian kuantitatif untuk mengetahui pengaruh kuantitas, kemampuan komunikasi interpersonal, dan perilaku altruisme anggota kelompok terhadap Social loafing pada mahasiswa Fakultas Kedokteran Universitas Udayana dengan menggunakan simple random sampling. Sebanyak 139 mahasiswa dari Program Studi Pendidikan Dokter dan Ilmu Keperawatan yang menjadi responden dalam penelitian ini. Alat ukur yang digunakan adalah Skala Social loafing dengan reliabilitas 0.918, Skala Komunikasi Interpersonal dengan reliabilitas 0.914, dan Skala Altruisme dengan reliabilitas 0.850. Hasil uji regresi berganda menunjukkan $\mathrm{R}=0.440$ dan adjusted $\mathrm{R}$ square sebesar 0.176 . Hal ini menunjukkan bahwa variabel kuantitas, kemampuan komunikasi interpersonal, dan perilaku altruisme anggota kelompok memiliki hubungan yang positif terhadap Social loafing dan memberikan pengaruh sebesar 17.6\% terhadap Social loafing. Berdasarkan hal tersebut, mahasiswa sangat disarankan untuk mempertahankan hubungan dengan sesama anggota kelompok melalui komunikasi interpersonal dan perilaku altruisme terutama saat melakukan diskusi kelompok, serta mempertahankan keaktifan dalam proses diskusi kelompok, karena diskusi kelompok merupakan salah satu media yang dapat mengasah kemampuan interpersonal dan mempertajam clinical/soft skill mahasiswa.
\end{abstract}

Kata kunci: Kuantitas, komunikasi interpersonal, altruisme, Social loafing

\begin{abstract}
Social loafing is individual's tendency to perform little effort toward group's achievement. Social loafing can harm other group members, since it creates imbalanced contribution and result achieved among individuals. Therefore, appropriate consideration to prevent the arising of Social loafing in a group is highly necessary. Some factors to consider are group size, interpersonal communication, and altruism behavior. This research is a quantitative research to investigate the influence of quantity, interpersonal communication ability, and altruism behavior of group members towards Social loafing on student in Faculty of Medicine, Udayana University by employing simple random sampling. The respondent of this research is 139 students of Medical Education and Nursing Study Program. Meanwhile, the measurement tool of this research is Social loafing Scale with the realibility 0.918, Interpersonal Communication Scale with the realibility 0.914 , and Alruism Scale with the realibility 0.850 . The result of multiple regression analysis indicates $\mathrm{R}=0.440$ and the adjusted $\mathrm{R}$ square is 0.176 . It indicates that the variable of quantity, interpersonal communication ability, and altruism behavior of group members have positive correlation to Social loafing and give influence $17.6 \%$ on Social loafing. Based on this, students are strongly advised to maintain relations with his fellow group members through interpersonal communication and behavior of altruism, especially during group discussions, as well as maintain the liveliness in the process of group discussion, as the discussion group is one medium that can hone interpersonal skills and sharpen clinical/soft skills of students.
\end{abstract}

Key words: Quantity, interpersonal communication, altruism behavior, Social loafing 


\section{LATAR BELAKANG}

Ilmu pengetahuan dan teknologi informasi akan terus berkembang dengan pesatnya. Hal tersebut memberikan dampak terhadap proses pendidikan karena, dengan adanya perkembangan dalam teknologi informasi mampu memberikan banyak cara bagi pelajar untuk mendapatkan informasi sumber belajar. Artinya, pelajar tidak hanya mendapatkan pengetahuan dari proses belajar secara formal, tetapi juga mendapat pengetahuan dari sumber-sumber pengetahuan lainnya. Hal tersebut dapat mengoptimalkan kemandirian pelajar dalam proses belajar (Kurdi, 2009). Adanya pengoptimalan kemandirian dalam diri pelajar merupakan implementasi dari metode pembelajaran SCL atau Student Centered Learning (Melyana, 2013). Student Centered Learning (SCL) merupakan metode belajar atau mengajar yang menjadikan pelajar sebagai pusat pembelajarannya (Machemer, 2007). Melalui SCL para pelajar memiliki keleluasaan untuk mengembangkan segenap potensi, membangun pengetahuan, dan mencapai kompetensi melalui proses pembelajaran aktif, interaktif, kolaboratif, kooperatif, kontekstual, dan mandiri (Harsono, 2008).

Di Indonesia, terdapat beberapa instansi pendidikan yang sudah menerapkan metode pembelajaran SCL. Menurut Nadjamuddin \& Norken (dalam Kurdi, 2009) Fakultas Kedokteran (FK) Universitas Udayana sudah menerapkan metode pembelajaran SCL. Selain itu, Fakultas Kedokteran dari Universitas Airlangga, Universitas Gadjah Mada, Universitas Syiah Kuala, dan Universitas Unika Atmajaya juga sudah menerapkan sistem SCL (Liansyah, 2015). Penerapan SCL dalam sekolah kedokteran sangat penting, karena untuk menciptakan tenaga medis yang handal, sekolah kedokteran tidak hanya terpaku pada pengajaran ilmu biomedis saja, tetapi juga mengembangkan clinical skill yang sangat dibutuhkan oleh masyarakat saat ini (Amin \& Eng, 2003). Penerapan metode SCL, khususnya pada sekolah kedokteran sudah menjadi urgensi yang disampaikan oleh organisasi kesehatan dunia, seperti World Health Organization (WHO) dan The Network: Towards Unity for Health untuk menghasilkan pekerja kesehatan sesuai dengan kebutuhan masyarakat dibidang kesehatan (Amin \& Eng, 2003).

Diperlukan pilar penunjang untuk menjamin terlaksananya metode pembelajaran SCL dalam sekolah kedokteran atau perguruan tinggi lainnya, pilar penunjang tersebut diantaranya adalah kerja kelompok (Melyana, 2013). Kerja kelompok tersebut sudah tercermin dalam jenis-jenis pembelajaran SCL, seperti small group discussion, cooperative learning, collaborative learning, role-play and simulation, dan project based learning (Dikti, 2004). Jenisjenis pembelajaran SCL tersebut sudah diimplementasikan oleh instansi pendidikan yang menerapkan sistem SCL, diantaranya Fakultas Kedokteran Universitas Udayana. Fakultas Kedokteran Universitas Udayana hingga saat ini masih menggunakan metode pembelajaran SCL, khususnya dengan sistem SGD atau small group discussion. SGD merupakan metode belajar dimana mahasiswa dibagi ke dalam beberapa kelompok kecil, yang biasanya terdiri dari empat sampai dengan sepuluh mahasiswa di dalamnya yang secara bersama-sama mendiskusikan materi yang akan dipelajari (Amin \& Eng, 2003).

Berdasarkan hal tersebut, pengerjaan tugas secara berkelompok merupakan komponen penting untuk diterapkan pada pendidikan tingkat universitas karena dengan adanya pengerjaan tugas secara berkelompok akan mendapatkan hasil yang lebih baik apabila dibandingkan ketika bekerja sendiri (Hall dan Buzwell, 2012). Hal ini didukung oleh pendapat Bolton (1999) yang menyatakan bahwa sebanyak $72 \%$ pengajar di universitas memberikan tugas secara berkelompok dalam proses perkuliahan. Adanya pemberian tugas secara berkelompok tersebut dapat meningkatkan partisipasi mahasiswa dalam proses belajar dan kerjasama (Sujarwo, 2013). Hasil dari diterapkannya kelompok dalam proses pembelajaran adalah meningkatnya kemampuan mahasiswa dalam komunikasi interpersonal (McCorkle dalam Hall \& Buzwell, 2012) dan perilaku tolong menolong dalam situasi sosial (Sujarwo, 2013).

Adanya proses kerjasama dari sejumlah orang untuk mencapai tujuan merupakan arti dari sebuah kelompok menurut Woodcock (dalam Stott \& Walker, 1995). Bekerja dalam lingkup kelompok di satu sisi dapat memudahkan penyelesaian masalah, namun pada sisi lainnya dapat memicu terjadinya penurunan motivasi individu karena kehadiran orang lain dalam kelompok. Penurunan motivasi individu ketika bekerja dalam kelompok disebut dengan Social loafing. Munculnya Social loafing dalam suatu kelompok dapat menghilangkan fungsi kelompok sebagai tempat yang efektif dan efisien untuk mencapai tujuan pembelajaran (Anggraeni dan Alfian, 2015).

Menurut hasil survei pada mahasiswa Fakultas Kedokteran Universitas Udayana, Social loafing memang terjadi dalam proses pembelajaran, khususnya dalam proses SGD, seperti mengabaikan tugas yang menjadi tanggung jawab mahasiswa tersebut (Pratama, 2015). Selain itu, hasil survei pada mahasiswa Fakultas Kedokteran Universitas Wijaya Kusuma Surabaya juga menyatakan bahwa Social loafing sering terjadi saat melakukan SGD dan perlu dicegah kemunculannya agar tidak terbiasa menjadi mahasiswa yang tidak bertanggung jawab dan tidak memiliki rasa empati terhadap rekan sejawat (Pratama, 2017). Sangatlah penting untuk mencegah munculnya Social loafing pada mahasiswa agar dapat mengurangi lulusan yang tidak berkualitas karena terbiasa untuk melepas tanggung jawab terhadap tugas dan tidak memiliki rasa empati terhadap orang lain. Berdasarkan data survei tersebut, diperlukan pertimbangan tepat terkait komposisi kelompok agar munculnya Social loafing dapat 


\section{PENGARUH KUANTITAS, KEMAMPUAN KOMUNIKASI INTERPERSONAL, DAN PERILAKU ALTRUISME ANGGOTA KELOMPOK TERHADAP SOCIAL LOAFING DALAM PROSES DISKUSI KELOMPOK DI FAKULTAS KEDOKTERAN UNIVERSITAS UDAYANA}

dikurangi dan seluruh anggota kelompok berkontribusi dalam proses mencapai tujuan.

Komposisi tersebut salah satunya dapat dilihat pada aspek jumlah anggota kelompok. Terdapat beberapa pendapat mengenai jumlah anggota yang efektif dalam sebuah kelompok, salah satunya adalah berjumlah lima sampai sembilan anggota (Robins \& Judge, 2013). Menurut Peterson (dalam Stott \& Walker, 1995) jumlah anggota kelompok yang efektif adalah berkisar antara enam sampai dengan 12 orang. Jika kelompok memiliki anggota kelompok kurang dari enam, maka kelompok tidak memperoleh rentang pendapat yang luas, sedangkan jika kelompok memiliki anggota kelompok lebih dari 12 orang, maka kelompok akan kesulitan dalam mencapai kesepakatan (Stott \& Walker, 1995).

Menurut hasil survei terhadap 15 mahasiswa Fakultas Kedokteran Universitas Udayana yang dilakukan pada hari Minggu, 6 Desember 2015, terdapat beberapa hal yang diungkapkan terkait dengan banyaknya jumlah anggota. Hasil survei menunjukkan bahwa jumlah anggota kelompok yang tepat adalah empat sampai dengan enam orang, sebab jika jumlah anggota berlebihan maka masalah yang muncul adalah kesulitan dalam mengatur anggota, ketidakseimbangan dalam pembagian tugas, dan ketidakefektifan karena banyak yang tidak bekerja dan berkontribusi kepada kelompok (Pratama, 2015). Berbeda dengan hasil survei dan teori, dalam praktiknya, Fakultas Kedokteran Universitas Udayana menerapkan kelompok dengan jumlah anggota sebanyak sembilan sampai dengan 15 orang. Berdasarkan hasil survei yang telah dilakukan, muncul sebuah permasalahan yakni semakin banyak anggota dalam kelompok akan mempersulit dalam proses pembagian tugas secara merata dan pada akhirnya dapat menghambat proses penyelesaian tugas karena partisipasi anggota kelompok yang tidak merata (Pratama, 2015). Ketidakmerataan partisipasi anggota kelompok tersebut dapat menurunkan partisipasi anggota kelompok, dan pada akhirnya Social loafing pun tidak dapat dihindari (Indik dalam Shaw, 1981). Timbulnya Social loafing dapat menyebabkan rendahnya ketertarikan individu untuk tinggal dalam kelompok atau yang disebut dengan kohesivitas (Anggraeni \& Alfian, 2015).

Terdapat faktor lain yang perlu dipertimbangkan agar kelompok menjadi lebih efektif dan kohesif. Faktor tersebut adalah komunikasi interpersonal. Komunikasi interpersonal merupakan penyampaian informasi dari satu orang kepada orang lain (Bochner, dalam DeVito, 2011). Menurut Wulansari, Hardjajani, \& Nugroho (2013) kohesivitas dan kinerja kelompok akan semakin baik jika komunikasi dalam kelompok dilakukan dengan baik, yang ditandai dengan mudah dipahaminya pesan oleh sesama anggota kelompok dan berkomunikasi dalam intonasi dan tempo yang tepat. Komunikasi interpersonal yang terjadi dalam proses SGD dapat berupa penyampaian pemikiran atau perasaan terhadap kelompok dan sikap saling mendukung atau menyanggah pemikiran anggota kelompok lainnya. Jika proses penyampaian pesan berupa pemikiran atau perasaan kepada kelompok dilakukan dengan baik, maka anggota kelompok lain dapat memahami, menyetujui, dan bahkan mengikuti apa yang disampaikan yang pada akhirnya dapat mengurangi timbulnya kesalahpahaman (Wulansari, dkk., 2013).

Terbentuknya suatu kelompok dapat meningkatkan perilaku altruisme dalam diri anggota kelompok (Sujarwo, 2013). Perilaku altruisme tersebut tercermin dalam perilaku saling membantu saat teman sekelompok belum memahami materi diskusi (Hapsari \& Yonata, 2014). Berdasarkan hal tersebut, dalam proses diskusi kelompok, mahasiswa tidak hanya melatih kemampuan komunikasi interpersonalnya, tetapi juga perilaku menolong atau altruisme. Perilaku menolong atau altruisme merupakan hasrat untuk menolong orang lain diatas kepentingan pribadi dan tidak mengharapkan imbalan (Myers, 2003). Faturochman (2009) menyatakan bahwa pada kelompok dengan kohesivitas tinggi, anggota kelompok merasa bahwa memberikan pertolongan kepada anggota kelompok merupakan sebuah tanggung jawab, sehingga perilaku menolong diperlukan dalam sebuah kelompok. Hal ini berkaitan dengan adanya diffusion of responsibility atau persebaran tanggung jawab dari diri individu saat berada dalam situasi sosial (Sarwono \& Meinarno, 2009).

Jika diffusion of responsibility dikaitkan dengan kelompok, maka tanggung jawab individu untuk menolong akan menurun karena terbagi dengan anggota kelompok yang berada disekitar diri individu tersebut. Adanya diffusion of responsibility inilah yang menyebabkan munculnya Social loafing, namun pada kelompok yang kohesif tidak terjadi diffusion of responsibility, karena saling menolong adalah tanggung jawab sesama anggota kelompok (Rutkowski, Cruder, \& Romer, 1983).

Berdasarkan penjelasan sebelumnya, dapat disimpulkan bahwa kuantitas anggota dalam suatu kelompok, komunikasi interpersonal, dan perilaku altruisme dapat berkontribusi terhadap kohesivitas kelompok. Jika kohesivitas sudah muncul dalam sebuah kelompok, maka kemungkinan terjadinya Social loafing dapat ditekan. Oleh karena itu, diperlukan sebuah penelitian yang mampu memberikan informasi mengenai pengaruh jumlah anggota kelompok, kemampuan komunikasi interpersonal, dan perilaku altruisme terhadap timbulnya Social loafing. Harapannya, hasil penelitian ini dapat menjadi pertimbangan dalam pembentukan kelompok SGD yang efektif. 


\section{METODE PENELITIAN}

\section{Variabel dan Definisi Operasional}

Variabel bebas dalam penelitian ini adalah kuantitas anggota kelompok, kemampuan komunikasi interpersonal, dan perilaku altruisme, sedangkan variabel terikat dalam penelitian ini adalah Social loafing. Adapun definisi operasional dari masing-masing variabel penelitian ialah sebagai berikut:

1. Kuantitas anggota kelompok merupakan jumlah anggota di dalam suatu kelompok. Dalam pelaksanaanya, variabel kuantitas dalam penelitian ini adalah variasi dari ukuran kelompok SGD di PSPD \& PSIK yang diukur dengan cara menghitung jumlah anggota dalam satu kelompok SGD.

2. Kemampuan komunikasi interpersonal dalam penelitian ini adalah kemampuan anggota kelompok dalam memberikan, memahami, dan menerima informasi yang diberikan secara tepat sehingga proses diskusi menjadi efektif. Kemampuan komunikasi interpersonal diukur dengan menggunakan skala komunikasi interpersonal yang disusun berdasarkan lima aspek komunikasi interpersonal dari DeVito (2011) yang terdiri atas keterbukaan, empati, sikap suportif, sikap positif, dan kesetaraan. Skor total aitem yang diperoleh menunjukkan kemampuan komunikasi interpersonal yang dimiliki responden. Semakin tinggi skor yang diperoleh maka semakin tinggi kemampuan komunikasi interpersonal responden penelitian.

3. Perilaku altruisme dalam penelitian ini merupakan kesediaan masing-masing anggota kelompok untuk saling membantu anggota kelompok lain yang mengalami kesulitan dalam proses diskusi, sehingga terjalin kerjasama yang baik antar anggota kelompok. Perilaku altruisme diukur dengan menggunakan skala perilaku altruisme yang disusun berdasarkan tiga aspek Cohen (dalam Nashori, 2008) yang terdiri atas empati, keinginan memberi, dan sukarela. Skor total aitem yang diperoleh menunjukkan perilaku altruisme yang dimiliki responden. Semakin tinggi skor yang diperoleh maka semakin tinggi perilaku altruisme responden penelitian.

4. Social loafing dalam penelitian ini merupakan kecenderungan individu untuk memberikan usaha yang sedikit saat bekerja dalam kelompok. Social loafing diukur dengan menggunakan skala Social loafing yang disusun berdasarkan dua aspek dari Social Impact Theory (dalam Chidambaram \& Tung, 2005) yang terdiri atas dilution effect dan immediacy gap. Skor total aitem yang diperoleh menunjukkan Social loafing yang dimiliki responden. Semakin tinggi skor yang diperoleh maka semakin tinggi Social loafing responden penelitian.

\section{Teknik Pengambilan Sampel}

Teknik sampling yang digunakan dalam penelitian ini adalah simple random sampling. Simple random sampling merupakan pengambilan anggota sampel dari populasi yang dilakukan secara acak tanpa memerhatikan strata yang ada di dalam populasi itu (Sugiyono, 2013). Penggunaan simple random sampling akan memberikan kesempatan yang sama kepada mahasiswa PSPD dan PSIK Fakultas Kedokteran Universitas Udayana untuk menjadi sampel dalam penelitian. Selain teknik sampling, perlu diperhatikan juga ukuran sampel. Terdapat tiga rumus dalam menentukan jumlah sampel minimum berdasarkan jumlah variabel bebas (VB) atau prediktornya (Field, 2009). Rumus tersebut yaitu:

1. VB $x$ 15, sehingga diperoleh jumlah sampel minimum sebanyak 45 .

2. $50+8 \times \mathrm{VB}$, sehingga diperoleh jumlah sampel minimum sebanyak 74 .

3. $104+$ VB, sehingga diperoleh jumlah sampel minimum sebanyak adalah 107 .

Berdasarkan rumus tersebut, jumlah minimal sampel yang digunakan dalam penelitian ini adalah sebanyak 107 mahasiswa Fakultas Kedokteran Universitas Udayana, karena Green (dalam Field, 2009) menyatakan bahwa semakin besar sampel yang digunakan akan semakin baik.

\section{Subjek dan Tempat Penelitian}

Populasi dalam penelitian ini adalah mahasiswa yang masih aktif melakukan SGD.. Sampel yang digunakan pada penelitian ini adalah mahasiswa Program Studi Pendidikan Dokter (PSPD) dan Program Studi Ilmu Keperawatan Fakultas Kedokteran Universitas Udayana angkatan 2014 dan 2015. Teknik pengambilan sampel untuk penelitian ini adalah simple random sampling, yaitu teknik pengambilan anggota sampel dari populasi yang dilakukan secara acak tanpa memerhatikan strata yang ada di dalam populasi itu. Teknik ini dipilih agar mahasiswa PSPD dan PSIK Fakultas Kedokteran Universitas Udayana memiliki kesempatan yang sama untuk menjadi sampel dalam penelitian. Cara pengambilan sampel pada penelitian ini adalah dengan melakukan open recruitment pada kelompok SGD yang bersedia mengikuti penelitian. Jumlah subjek dalam penelitian ini adalah 200 orang. Proses pengambilan data dilakukan di PSPD dan PSIK Fakultas Kedokteran Universitas Udayana, di ruang SGD pada bulan November 2016.

\section{Alat Ukur}

Alat ukur yang digunakan dalam penelitian ini adalah skala Social loafing, skala Komunikasi Interpersonal dan skala Altruisme. Skala Social loafing disusun berdasarkan dua aspek Social Impact Theory (Chidambaram \& Tung, 2005), skala Komunikasi Interpersonal disusun berdasarkan lima aspek komunikasi interpersonal dari DeVito (2011), dan skala Altruisme disusun berdasarkan tiga aspek altruisme menurut Cohen (dalam Nashori, 2008). Skala Social loafing terdiri dari 22 aitem pernyataan, skala Komunikasi Interpersonal terdiri dari 31 aitem pernyataan, dan skala Altruisme terdiri dari 12 
pernyataan. Skala Social loafing, skala Komunikasi Interpersonal, dan skala Altruisme disusun dalam bentuk pernyataan favorable dan unfavorable yang diberi skor mulai dari 1 sampai 4. Pada skala Social loafing, skala Komunikasi Interpersonal, dan skala Altruisme terdapat 4 respon jawaban, yaitu sangat sesuai (SS), sesuai (S), tidak sesuai (TS), dan sangat tidak sesuai (STS). Pernyataan dalam aitem favorable jawaban sangat setuju (SS) diberi skor 4, setuju (S) diberi skor 3, tidak setuju (TS) diberi skor 2, dan sangat tidak setuju (STS) diberi skor 1. Pernyataan dalam aitem unfavorable jawaban sangat setuju (SS) diberi skor 1, setuju (S) diberi skor 2, tidak setuju (TS) diberi skor 3, dan sangat tidak setuju (STS) diberi skor 4.

Rentang nilai koefisien korelasi aitem total skala Social loafing pada saat pengujian validitas berada dari rentang 0.321-0.712. Hasil reliabilitas skala Social loafing dengan menggunakan Cronbach Alpha $(\alpha)$ adalah sebesar 0.918. Alpha $(\alpha)$ sebesar 0.918 menunjukkan bahwa $91.8 \%$ variasi skor subjek pada skala ini adalah skor murni. Hasil tersebut menggambarkan bahwa skala Social loafing dapat digunakan untuk mengukur tingkat Social loafing.

Rentang nilai koefisien korelasi aitem total skala Komunikasi Interpersonal pada saat pengujian validitas berada dari rentang 0.312-0.676. Hasil reliabilitas skala Komunikasi Interpersonal dengan menggunakan Cronbach Alpha $(\alpha)$ adalah sebesar 0.914. Alpha $(\alpha)$ sebesar 0.914 menunjukkan bahwa $91.4 \%$ variasi skor subjek pada skala ini adalah skor murni. Hasil tersebut menggambarkan bahwa skala Komunikasi Interpersonal dapat digunakan untuk mengukur kemampuan komunikasi interpersonal.

Rentang nilai koefisien korelasi aitem total skala Altruisme pada saat pengujian validitas berada dari rentang 0.412-0.646. Hasil reliabilitas skala Altruisme dengan menggunakan Cronbach Alpha $(\alpha)$ adalah sebesar 0.85. Alpha $(\alpha)$ sebesar 0.85 menunjukkan bahwa $85 \%$ variasi skor subjek pada skala ini adalah skor murni. Hasil tersebut menggambarkan bahwa skala Altruisme dapat digunakan untuk mengukur Altruisme.

\section{Teknik Analisis Data}

Teknik analisis yang digunakan untuk dapat menguji hipotesis dalam penelitian ini adalah regresi berganda. Teknik analisis regresi berganda merupakan teknik statistik parametrik. Analisis ini digunakan untuk menguji hipotesis pada penelitian yang menggunakan dua atau lebih variabel bebas untuk melakukan prediksi terhadap variabel tergantung (Field, 2009).

\section{HASIL PENELITIAN}

Diketahui bahwa sebanyak 200 responden penelitian tersebar dari angkatan 2014 sampai 2015. Mayoritas responden adalah berjenis kelamin perempuan, sedangkan jika dilihat berdasarkan usia, responden mayoritas berusia 20 tahun.

\begin{tabular}{cccc} 
Deskripsi Data Penelitian & $\begin{array}{c}\text { Tabel 1. } \\
\text { Deskripsi Data Penelitian }\end{array}$ \\
\hline & Komunikasi & Altruisme & Social Loafing \\
\hline Deskripsi Data & Interpersonal & 139 & 139 \\
N & 139 & 30 & 55 \\
Rata-rata Teoretis & 80 & 34.94 & 41.06 \\
Rata-rata Empiris & 92.16 & 6 & 11 \\
SD Teoretis & 16 & 2.503 & 7.975 \\
SD Empiris & 5.442 & 29 & 22 \\
Xmin & 74 & 41 & 62 \\
Xmax & 105 & $12-48$ & $22-88$ \\
Sebaran Teoretis & $32-128$ & $29-41$ & $22-62$ \\
Sebaran Empiris & $74-105$ & &
\end{tabular}

Pada rangkuman data deskripsi pada tabel 1 , terlihat bahwa perbedaan rata-rata empiris dan rata-rata teoritis pada variabel komunikasi interpersonal sebesar 13.94. Rata-rata empiris yang lebih tinggi dari rata-rata teoritis, menunjukkan bahwa responden memiliki kemampuan komunikasi interpersonal yang tinggi. Rentang skor subjek penelitian antara 74 sampai 105. Kategorisasi komunikasi interpersonal berdasarkan rata-rata teoritis adalah tidak ada responden dengan komunikasi interpersonal pada kategori sangat rendah dan rendah, pada katagori sedang sebanyak 29 responden (20.86\%), pada kategori tinggi sebanyak 109 responden (78.42\%), dan pada kategori sangat tinggi sebanyak 1 responden $(0.72 \%)$. Oleh karena itu, dapat disimpulkan bahwa mayoritas responden tergolong dalam kategorisasi komunikasi interpersonal yang tinggi. Kategorisasi komunikasi interpersonal dapat dilihat pada tabel 2.

\begin{tabular}{cccc}
\multicolumn{4}{c}{ Tabel 2. } \\
& Kategorisasi Komunikasi Interpersonal \\
\hline Rentang Nilai & Kategori & Jumlah & Persentase \\
\hline $\mathrm{X} \leq 56$ & Sangat Rendah & 0 & $0 \%$ \\
$56<\mathrm{X} \leq 72$ & Rendah & 0 & $0 \%$ \\
$72<\mathrm{X} \leq 88$ & Sedang & 29 & $20.86 \%$ \\
$88<\mathrm{X} \leq 104$ & Tinggi & 109 & $78.42 \%$ \\
$104<\mathrm{X}$ & Sangat Tinggi & 1 & $0.72 \%$ \\
\hline
\end{tabular}

Pada rangkuman data deskripsi pada tabel 1 , terlihat bahwa perbedaan rata-rata empiris dan rata-rata teoritis pada variabel altruisme sebesar 4.94. Rata-rata empiris yang lebih tinggi dari rata-rata teoritis, menunjukkan bahwa responden memiliki altruisme yang tinggi. Rentang skor subjek penelitian antara 29 sampai 41. Kategorisasi altruisme berdasarkan rata-rata teoritis adalah tidak ada responden dengan altruisme pada kategori sangat rendah dan rendah, pada katagori sedang sebanyak 37 responden $(26.62 \%)$, pada kategori tinggi sebanyak 97 responden (69.78\%), dan pada kategori sangat tinggi sebanyak 5 responden $(3.6 \%)$. Oleh karena itu, dapat disimpulkan bahwa mayoritas responden tergolong dalam kategorisasi altruisme yang tinggi. Kategorisasi altruisme dapat dilihat pada tabel 3.

\section{Karakteristik Responden}


Tabel 3.

Kategorisasi Altruisme

\begin{tabular}{cccc} 
& & & \\
\hline Rentang Nilai & Kategori & Jumlah & Persentase \\
\hline $\mathrm{X} \leq 21$ & Sangat Rendah & 0 & $0 \%$ \\
$21<\mathrm{X} \leq 27$ & Rendah & 0 & $0 \%$ \\
$27<\mathrm{X} \leq 33$ & Sedang & 37 & $26.62 \%$ \\
$33<\mathrm{X} \leq 39$ & Tinggi & 97 & $69.78 \%$ \\
$39<\mathrm{X}$ & Sangat Tinggi & 5 & $3.6 \%$ \\
\hline
\end{tabular}

Pada rangkuman data deskripsi pada tabel 1, terlihat bahwa perbedaan rata-rata empiris dan rata-rata teoritis pada variabel Social loafing sebesar 4.94. Rata-rata empiris yang lebih rendah dari rata-rata teoritis, menunjukkan bahwa responden memiliki Social loafing yang rendah. Rentang skor subjek penelitian antara 22 sampai 62. Kategorisasi Social loafing berdasarkan rata-rata teoritis adalah tidak ada responden dengan altruisme pada kategori sedang, tinggi, dan sangat tinggi, pada katagori rendah sebanyak 10 responden (7.2\%), dan pada kategori sangat rendah sebanyak 129 responden (92.8\%). Oleh karena itu, dapat disimpulkan bahwa mayoritas responden tergolong dalam kategorisasi Social loafing yang sangat rendah. Kategorisasi Social loafing dapat dilihat pada tabel 4 .

\begin{tabular}{cccc}
\multicolumn{4}{c}{ Tabel 4. } \\
& Kategorisasi Social Loafing \\
\hline Rentang Nilai & Kategori & Jumlah & Persentase \\
\hline $\mathrm{X} \leq 38,5$ & Sangat Rendah & 129 & $92.8 \%$ \\
$38,5<\mathrm{X} \leq 49,5$ & Rendah & 10 & $7.2 \%$ \\
$49,5<\mathrm{X} \leq 60,5$ & Sedang & 0 & $0 \%$ \\
$60,5<\mathrm{X} \leq 71,5$ & Tinggi & 0 & $0 \%$ \\
$71,5<\mathrm{X}$ & Sangat Tinggi & 0 & $0 \%$ \\
\hline
\end{tabular}

\section{Uji Asumsi}

Hasil uji normalitas pada penelitian ini dapat dilihat pada tabel berikut.

\begin{tabular}{cccc}
\multicolumn{4}{c}{ Tabel 5. } \\
Hasil Uji Normalitas \\
\hline Kolmogorov-Simirnov & $\mathrm{P}$ & Kesimpulan \\
\hline Skala & 1.195 & 0.115 & Data Normal \\
Komunikasi Interpersonal & 1.097 & 0.180 & Data Normal \\
Altruisme & 1.346 & 0.053 & Data Normal \\
Kuantitas kelompok & 1.111 & 0.169 & Data Normal \\
Social loafing & 0.903 & 0.389 & Data Normal \\
Residual & &
\end{tabular}

Uji Normalitas dalam uji regresi berganda dilihat dari nilai residual dari variabel bebas (Ghozali, 2016). Berdasarkan tabel diatas, nilai residual dari variabel kemampuan komunikasi interpersonal, perilaku altruisme, dan kuantitas memiliki signifikansi sebesar 0.389 (>0.05). Hal ini menunjukkan bahwa nilai residual dalam penelitian ini berdistribusi normal.

\begin{tabular}{ccc} 
Tabel 6. & \\
Hasil Uji Linieritas \\
\hline Skala & Sig & Simpulan \\
\hline Komunikasi interpersonal*social loafing & 0,710 & Data Linier \\
Altruisme* social loafing & 0,126 & Data Linier \\
Kuantitas anggota kelompok* social loafing & 0,715 & Data Linier \\
\hline Berdasarkan tabel & diatas & Variabel Variabel
\end{tabular}

kemampuan komunikasi interpersonal terhadap Social loafing, perilaku altruisme terhadap Social loafing, dan kuantitas terhadap Social loafing memiliki nilai deviation from linearity sebesar 0.710, 0.126, dan 0.715 (>0.05). Hal ini menunjukkan bahwa data ketiga variabel dalam penelitian ini memiliki hubungan yang linier terhadap variabel tergantung.
Tabel 7.

Hasil Uji Multikolinieritas

\begin{tabular}{|c|c|c|c|}
\hline Variabel & Tolerance & $V I F$ & Simpulan \\
\hline Komunikasi interpersonal & 0.819 & 1.222 & $\begin{array}{c}\text { Tidak terjadi } \\
\text { multikolinieritas }\end{array}$ \\
\hline Altruisme & 0.821 & 1.218 & $\begin{array}{c}\text { Tidak terjadi } \\
\text { multikolinieritas }\end{array}$ \\
\hline Kuantitas anggota kelompok & 0.974 & 1.026 & $\begin{array}{c}\text { Tidak terjadi } \\
\text { multikolinieritas }\end{array}$ \\
\hline
\end{tabular}

Berdasarkan tabel diatas variabel kemampuan komunikasi interpersonal, perilaku altruisme, dan kuantitas memiliki nilai tolerance masing-masing sebesar 0.819, 0.821, 0.974 (>0.1) serta nilai VIF masing-masing sebesar 1.222, 1.218, 1.026 (<10). Hal ini menunjukkan tidak ada multikolinearitas antar variabel bebas dalam penelitian ini.

\begin{tabular}{|c|c|c|c|c|c|c|}
\hline \multicolumn{7}{|c|}{$\begin{array}{l}\text { Tabel } 8 . \\
\text { Hasil Uji Heteroskedastisitas }\end{array}$} \\
\hline & Model & Unstandardized & Coefficients & $\begin{array}{c}\text { Standardized } \\
\text { Coefficients }\end{array}$ & $T$ & Sig. \\
\hline \multirow{5}{*}{1} & & $\mathrm{~B}$ & Std. ErTor & Beta & & \\
\hline & (Constant) & -7.015 & 7.600 & & -.923 & .358 \\
\hline & Komunikasi & .110 & .081 & .128 & 1.363 & .175 \\
\hline & Altruisme & .065 & .176 & .035 & .368 & .714 \\
\hline & $\begin{array}{c}\text { Ukuran } \\
\text { kelompok }\end{array}$ & -.002 & .240 & -.001 & -.009 & .993 \\
\hline
\end{tabular}

Berdasarkan tabel diatas, nilai signifikansi variabel kemampuan komunikasi interpersonal, perilaku altruisme, dan kuantitas menunjukkan hasil yang tidak signifikan (>0.05). Hal ini menunjukkan tidak terjadi heteroskedastisitas pada model regresi dalam penelitian ini.

\begin{tabular}{cccccc}
\multicolumn{7}{c}{ Tabel 9. } \\
Hasil Uji Autokorelasi \\
\hline Model & $\mathrm{R}$ & $\mathrm{R}$ Square & $\begin{array}{c}\text { Adjusted } \mathrm{R} \\
\text { Square }\end{array}$ & $\begin{array}{c}\text { Std. Error of } \\
\text { the Estimate }\end{array}$ & $\begin{array}{c}\text { Durbin- } \\
\text { Watson }\end{array}$ \\
\hline 1 & $.440^{2}$ & .194 & .176 & 7.241 & 1.832 \\
\hline
\end{tabular}

Berdasarkan tabel diatas, nilai Durbin Watson sebesar 1.832. Nilai DU diperoleh dari tabel Durbin Watson yang didasari pada jumlah variabel bebas dan sampel yang digunakan dalam penelitian ini. Penelitian ini menggunakan tiga variabel bebas dengan jumlah sampel 139, sehingga nilai DU pada penelitian ini adalah 1.638. Nilai Durbin Watson 1.832 lebih besar dari 1.638 dan 1.832 lebih kecil dari 2.362 (4-DU). Hal ini menunjukkan bahwa tidak terdapat autokorelasi dalam penelitian ini.

\section{Uji Hipotesis}

Uji hipotesis dalam penelitian ini menggunakan uji regresi berganda.

\begin{tabular}{|c|c|c|c|c|c|c|}
\hline \multicolumn{7}{|c|}{$\begin{array}{l}\text { Tabel } 10 . \\
\text { Hasil Signifikansi } \\
\end{array}$} \\
\hline & & $\begin{array}{l}\text { Sum of } \\
\text { Squares }\end{array}$ & $d f$ & Mean Square & F & Sig. \\
\hline \multirow{3}{*}{1} & Regression & 1700.167 & 2 & 566.722 & 123.608 & .000 \\
\hline & Residual & 7077.373 & 240 & 52.425 & & \\
\hline & Total & 8777.540 & 242 & & & \\
\hline
\end{tabular}

Berdasarkan tabel diatas diperoleh nilai signifikansi sebesar $0.000 \quad(<0.05)$. hal tersebut menunjukkan bahwa variabel kemampuan komunikasi interpersonal, perilaku altruisme, dan kuantitas diyakini dapat memprediksi variabel Social loafing.

Tabel 11.

Besaran Sumbangan Variabel Bebas terhadap Variabel Tergantung

\begin{tabular}{ccccc}
\hline Model & $\mathrm{R}$ & R Square & Adjusted R Square & Std. Error of the Estimate \\
\hline 1 & 0.440 & 0.194 & 0.176 & 7.241 \\
\hline
\end{tabular}




\section{PENGARUH KUANTITAS, KEMAMPUAN KOMUNIKASI INTERPERSONAL, DAN PERILAKU ALTRUISME ANGGOTA KELOMPOK TERHADAP SOCIAL LOAFING DALAM PROSES DISKUSI KELOMPOK DI FAKULTAS KEDOKTERAN UNIVERSITAS UDAYANA}

Berdasarkan tabel diatas diperoleh nilai $\mathrm{R}$ sebesar 0.440. Hal ini menunjukkan terdapat hubungan antara variabel kuantitas, kemampuan komunikasi interpersonal, dan perilaku altruisme terhadap Social loafing. Berdasarkan tabel 11, diperoleh juga nilai adjusted $\mathrm{R}$ square sebesar 0.176. Hal ini menunjukkan sumbangan efektif dari variabel kuantitas, kemampuan komunikasi interpersonal, dan perilaku altruisme terhadap Social loafing yaitu sebesar $17.6 \%$.

\begin{tabular}{|c|c|c|c|c|c|c|}
\hline & \multirow[t]{2}{*}{ Model } & \multicolumn{2}{|c|}{$\begin{array}{l}\text { Unstandardized } \\
\text { Coefficients }\end{array}$} & \multirow{2}{*}{$\begin{array}{c}\text { Standardized } \\
\text { Coefficients } \\
\text { Beta }\end{array}$} & \multirow[t]{2}{*}{$t$} & \multirow[t]{2}{*}{ Sig. } \\
\hline & & B & Std. Error & & & \\
\hline \multirow{4}{*}{1} & (Constant) & 100.090 & 11.741 & & 8.525 & .000 \\
\hline & $\begin{array}{l}\text { Komunikasi } \\
\text { Interpersonal }\end{array}$ & -.647 & .125 & -.442 & -5.171 & .000 \\
\hline & Altruisme & .003 & .272 & .001 & .010 & .992 \\
\hline & Kuantitas & .044 & .371 & .009 & .119 & .905 \\
\hline
\end{tabular}

Berdasarkan tabel diatas, koefisien signifikansi variabel kuantitas, kemampuan komunikasi interpersonal, dan perilaku altruisme adalah sebesar 0.000, 0.992, dan 0.905 . Nilai $0.000(\mathrm{p}<0.05)$ pada variabel komunikasi interpersonal memiliki arti bahwa variabel komunikasi interpersonal memberikan pengaruh dengan variabel Social loafing. Variabel perilaku altruisme dan kuantitas anggota kelompok menunjukkan signifikasi sebesar 0.992 dan 0.905 ( $p>0.05$ ). Hal ini menunjukkan bahwa perilaku altruisme dan kuantitas anggota tidak memberikan pengaruh terhadap Social loafing. Berdasarkan tabel diatas ditemukan pula bahwa skor prestasi belajar dapat diramalkan melalui rumus berikut.

$\mathrm{Y}=100.090-0.647 \mathrm{X} 1+0.003 \mathrm{X} 2+0.044 \mathrm{X} 3$

Pada rumus tersebut, Y menjelaskan skor Social loafing, X1 menjelaskan skor komunikasi interpersonal, X2 menjelaskan skor perilaku altruism, dan X3 menjelaskan skor kuantitas anggota kelompok. Garis regresi tersebut memiliki arti sebagai berikut.

1. Konstanta sebesar 100.090 mununjukan bahwa jika tidak ada kuantitas, kemampuan komunikasi interpersonal, dan perilaku altruisme anggota kelompok, Social loafing yang dimiliki mahasiswa cenderung tinggi yaitu sebesar 100.090.

2. Koefisien regresi X1 sebesar -0.647 menunjukkan bahwa setiap penambahan satuan nilai dari kemampuan interpersonal, maka akan menurunkan nilai Social loafing sebesar 0.647 satuan.

3. Koefisien regresi X2 sebesar 0.003 menunjukkan bahwa setiap penambahan satuan nilai dari perilaku altruisme, maka akan meningkatkan nilai Social loafing sebesar 0.003 satuan.

4. Koefisien regresi X3 sebesar 0.044 menunjukkan bahwa setiap penambahan satuan nilai dari kuantitas kelompok, maka akan meningkatkan nilai Social loafing sebesar 0.044 satuan.

\section{PEMBAHASAN DAN KESIMPULAN}

Berdasarkan uji regresi berganda yang dilakukan, diperoleh hasil bahwa kuantitas, kemampuan komunikasi interpersonal, dan perilaku altruisme anggota kelompok berpengaruh terhadap timbulnya Social loafing. Faktor pertama yang diteliti dalam penelitian ini adalah faktor kuantitas anggota kelompok atau ukuran kelompok. Ukuran kelompok merupakan salah satu faktor yang perlu dipertimbangkan dalam membentuk sebuah kelompok, karena menurut Yang (dalam Harris \& Sherblom, 2008) faktor ukuran kelompok dapat menjadi bumerang bagi kelompok itu sendiri. Artinya, semakin banyak jumlah anggota dalam suatu kelompok, maka kelompok tersebut akan kesulitan dalam mengatur interaksi antar sesama anggota kelompok. Selain itu, apabila jumlah anggota kelompok semakin besar, dapat memicu munculnya sub-sub kelompok serta konflik dalam kelompok, yang kemudian mengarahkan kepada permasalahan yang lebih besar (Shaw, 1981).

Hasil analisis koefisien beta terstandarisasi dari kuantitas anggota kelompok menunjukkan arti bahwa kuantitas anggota kelompok tidak memberikan pengaruh terhadap munculnya Social loafing pada mahasiswa Fakultas Kedokteran Universitas Udayana. Hasil ini juga diperkuat oleh hasil uji ANOVA yang menunjukkan bahwa tidak adanya perbedaan nilai rata-rata pada tujuh kategori kuantitas anggota kelompok terhadap Social loafing. Berdasarkan hal tersebut, tidak adanya perbedaan yang signifikan dari nilai rata-rata pada kuantitas anggota kelompok menyebabkan faktor kuantitas kelompok tidak memiliki pengaruh terhadap Social loafing.

Tidak adanya pengaruh kuantitas anggota kelompok terhadap Social loafing dikarenakan jumlah anggota kelompok yang ada pada SGD di Fakultas Kedokteran Universitas Udayana masih tergolong dalam ukuran kelompok yang optimal. Hal ini didukung oleh pendapat Davis, dkk (1992) yang menyatakan bahwa jumlah anggota kelompok sebanyak 15 orang adalah jumlah maksimal untuk menciptakan kelompok yang optimal. Selain itu, hasil penelitian ini juga didukung oleh Petty (dalam Alnuami, Robert, \& Maruping, 2010) yang menyatakan bahwa saat jumlah anggota kelompok ditingkatkan menjadi 16 orang terjadi penurunan usaha yang signifikan dari masing-masing anggota kelompok. Artinya, saat kelompok memiliki anggota melebihi 15 orang akan menyebabkan terjadinya penurunan usaha dari anggota kelompok. Peningkatan jumlah anggota dalam sebuah kelompok, menyebabkan banyaknya ketersediaan SDM bagi kelompok untuk mencapai tujuan. Banyaknya ketersediaan SDM dalam kelompok inilah yang dapat memunculkan pemikiran bahwa anggota kelompok hanya memiliki sedikit tanggung jawab untuk mencapai tujuan kelompok dan cenderung melempar tanggung jawab tersebut kepada anggota 
kelompok lainnya dengan cara mengurangi usahanya (Alnuami, dkk, 2010).

Selain ukuran kelompok yang tergolong optimal, tidak adanya pengaruh kuantitas anggota kelompok terhadap Social loafing dapat disebabkan oleh tipe tugas yang dikerjakan dalam kelompok (Alnuami, dkk, 2010). Dalam proses SGD yang dilakukan di Fakultas Kedokteran Universitas Udayana, permasalahan-permasalahan yang menjadi topik bahasan akan dijawab oleh masing-masing anggota terlebih dahulu dalam SGD. Kemudian jawaban tersebut dipadukan sehingga memunculkan kesimpulan baru yang kelompok SGD rasakan tepat sebagai solusi permasalahan. Jika dikaitkan dengan tipe tugas menurut Steiner (dalam Shaw, 1981), tipe tugas yang diterapkan dalam proses SGD di Fakultas Kedokteran Universitas Udayana adalah additive task. Additive task memiliki ciri-ciri adanya kontribusi jawaban atau solusi dari seluruh anggota kelompok yang pada gilirannya jawaban tersebut akan dipadukan dan menjadi jawaban kelompok. Menurut Shaw (1981), saat tugas yang diterapkan adalah additive task, performa kelompok akan meningkat seiring dengan meningkatnya jumlah anggota kelompok. Hal ini dikarenakan semakin banyaknya kontribusi yang diberikan dari masing-masing anggota kelompok saat jumlah anggota kelompok ditingkatkan. Jika dikaitkan dengan Social loafing, adanya peningkatan jumlah anggota kelompok yang mengerjakan additive task dapat menimbulkan persepsi bahwa masukan dari anggota lain berkaitan dengan hasil anggota kelompok lainnya (Karau \& Williams, 1993). Berdasarkan hal tersebut, setiap anggota memberikan usaha terbaiknya untuk mencapai tujuan kelompok, dan dengan adanya pemberian usaha dari setiap anggota kelompok dapat mengurangi terjadinya Social loafing.

Faktor kedua yang diteliti dalam penelitian ini adalah faktor kemampuan komunikasi interpersonal anggota kelompok. Proses diskusi kelompok yang dilakukan, komunikasi merupakan salah satu hal yang penting. Menurut Likert (dalam Rakhmat, 2015), efisiensi komunikasi interpersonal sangat berkaitan erat dengan kohesifitas kelompok. Artinya jika semakin kohesif kelompok tersebut, maka komunikasi interpersonal yang dilakukan akan semakin efektif. Semakin efektifnya komunikasi intepersonal pada kelompok yang kohesif dicirikan dengan adanya komunikasi interpersonal yang lebih bebas, lebih terbuka, dan lebih sering (Rakhmat, 2015). Selain itu, adanya komunikasi interpersonal yang efektif dapat mengarahkan anggota kelompok untuk menunjukkan perilaku-perilaku yang mendukung tujuan kelompok. Hal ini sejalan dengan Liliweri (dalam Wulansari, dkk, 2013) yang menyatakan bahwa dengan adanya komunikasi yang efektif dapat memengaruhi pengetahuan seseorang agar memperoleh kesamaan makna.

Hasil analisis koefisien beta terstandarisasi dari kemampuan komunikasi interpersonal menunjukkan bahwa kemampuan komunikasi interpersonal memberikan pengaruh terhadap munculnya Social loafing pada mahasiswa Fakultas Kedokteran Universitas Udayana. Adanya pengaruh komunikasi interpersonal terhadap munculnya Social loafing dikarenakan komunikasi interpersonal yang efektif dapat menyebabkan kelompok menjadi lebih kohesif. Anantaraman (dalam Shaw, 1981) menyatakan bahwa kelompok yang kohesif dicirikan dengan adanya kepuasan pada masingmasing anggota kelompok terhadap kelompoknya. Kepuasan tersebut menyebabkan anggota kelompok lebih berani dalam menanyakan informasi yang diperlukan untuk mencapai tujuan kelompok. Berdasarkan penjelasan tersebut, adanya komunikasi interpersonal menyebabkan kelompok menjadi lebih kohesif. Kohesivitias kelompok tersebut dapat mengurangi munculnya Social loafing. Penelitian lain menunjukkan bahwa dalam sebuah organisasi kemahasiswaan, Social loafing terjadi akibat kurangnya koordinasi dan komunikasi dalam melaksanakan tugas serta tidak adanya rasa saling mendukung antar anggota organisasi (Wildanto, 2016). Hal tersebut menunjukkan bahwa faktor komunikasi interpersonal memiliki pengaruh terhadap munculnya Social loafing dalam kelompok.

Faktor ketiga yang diteliti dalam penelitian ini adalah perilaku altruisme pada anggota kelompok. Perilaku altruisme sangat penting untuk diterapkan dalam kelompok, khususnya dalam proses SGD. Berkaitan dengan proses SGD, perilaku altruisme dapat berupa perilaku saling membantu teman sekelompok yang kurang atau belum memahami materi diskusi dan saling membantu dalam proses pemecahan masalah. Perilaku altruisme yang ditunjukkan masing-masing anggota kelompok dapat menyebabkan kelompok semakin kohesif. Hal ini disebabkan karena setiap anggota kelompok sudah saling mengenal, sehingga memberikan pertolongan pada teman sekelompok lainnya merupakan tanggung jawab dan kewajiban. Hal ini sesuai dengan Faturochman (2009) yang menyatakan bahwa pada kelompok dengan kohesivitas tinggi, anggota kelompok merasa bahwa memberikan pertolongan kepada anggota kelompok merupakan sebuah tanggung jawab, sehingga perilaku menolong diperlukan dalam sebuah kelompok. Hasil analisis koefisien beta terstandarisasi dari perilaku altruisme menunjukkan bahwa perilaku altruisme tidak memberikan pengaruh terhadap munculnya Social loafing pada mahasiswa Fakultas Kedokteran Universitas Udayana.

Dari hasil uji regresi berganda yang dilakukan, terdapat $82.4 \%$ sumbangan dari faktor lain terhadap munculnya Social loafing selain faktor yang menjadi prediktor dalam penelitian ini. Faktor tersebut diantaranya faktor jenis kelamin dan faktor budaya. Faktor jenis kelamin memiliki peran terhadap kecenderungan melakukan Social loafing. Hal tersebut didukung oleh Karau \& Williams (1993) yang menyatakan bahwa laki-laki lebih cenderung melakukan 
Social loafing daripada perempuan. Hal ini disebabkan karena laki-laki memiliki tingkat independen dan asertif yang tinggi, sedangkan perempuan lebih bijaksana dan peduli terhadap orang lain. Karau \& Willams (1993) juga menambahkan bahwa Social loafing lebih sering muncul pada kelompok yang anggotanya hanya laki-laki saja dibandingkan dengan kelompok yang terdiri dari laki-laki dan perempuan atau kelompok yang hanya terdiri dari perempuan saja. Hasil analisis tambahan yang diperoleh dalam penelitian ini, faktor jenis kelamin tidak memberikan pengaruh terhadap munculnya Social loafing. Tidak adanya pengaruh jenis kelamin terhadap Social loafing disebabkan oleh distribusi mahasiswa berdasarkan jenis kelamin dalam sebuah kelompok SGD di Fakultas Kedokteran Universitas Udayana. Artinya, dalam satu kelompok SGD tidak hanya terdiri dari jenis kelamin laki-laki atau perempuan saja, namun terdiri dari lakilaki dan perempuan. Berdasarkan pemaparan tersebut, faktor jenis kelamin tidak memiliki pengaruh terhadap Social loafing. Hal ini sejalan dengan pendapat Karau \& Williams (1993) yang menyatakan bahwa kelompok yang terdiri dari jender laki-laki dan perempuan lebih jarang menunjukkan Social loafing.

Faktor lainnnya yang berpengaruh adalah faktor budaya. Faktor budaya yang dimaksud adalah budaya individualis dan kolektivis. Pada budaya kolektivis, Social loafing tidak terjadi karena pada budaya tersebut menjunjung tinggi nilai kebersamaan, sedangkan pada budaya individualis Social loafing lebih banyak terjadi saat tujuan kelompok tidak relevan dengan tujuan pribadi (Earley, 1989). Rendahnya kemungkinan melakukan Social loafing pada budaya kolektivis disebabkan oleh adanya pemikiran bahwa kepentingan bersama diatas kepentingan pribadi, sehingga individu cenderung memberikan usaha terbaiknya untuk mencapai kepentingan bersama. Adanya pemberian usaha individu untuk kepentingan kelompok mencerminkan rendahnya Social loafing pada budaya kolektivis.

Hal lain yang dapat menjelaskan keterkaitan faktor budaya kolektivis terhadap Social loafing adalah konsep the self (Markus \& Kitayama, 1991). Pada budaya kolektivis terdapat keterikatan satu orang dengan orang lain atau interdependent self. Artinya, masyarakat kolektivis lebih menekankan pada pentingnya persamaan pemikiran dan perasaan yang dialami kelompok dan anggapan bahwa dirinya akan memperoleh manfaat jika kelompoknya juga mendapatkan manfaat. Berdasarkan hal tersebut, rendahnya kemunculan Social loafing pada masyarakat kolektivis disebabkan oleh adanya keinginan diri untuk memberikan manfaat kepada kelompok. Pemberian manfaat tersebut menyebabkan individu harus meningkatkan usahanya agar manfaat tersebut dapat terealisasi. Adanya peningkatan usaha individu tersebut dapat mengurangi munculnya Social loafing.
Berdasarkan penelitian yang telah dilakukan dan hasil analisis data statistik dapat ditarik kesimpulan, yaitu kuantitas, kemampuan komunikasi interpersonal, dan perilaku altruisme anggota kelompok memiliki hubungan yang positif dan mampu memprediksi timbulnya Social loafing. Variabel kuantitas, kemampuan komunikasi interpersonal, dan perilaku altruisme anggota kelompok tersebut memberikan pengaruh sebesar $17.6 \%$ terhadap Social loafing, sedangkan $82.4 \%$ dipengaruhi variabel lainnya. Secara spesifik, faktor komunikasi interpersonal memiliki pengaruh sebesar $64.7 \%$ terhadap penurunan Social loafing, sedangkan kuantitas dan perilaku altruisme anggota kelompok tidak berpengaruh terhadap Social loafing. Kemampuan komunikasi interpersonal dan perilaku altruisme pada mahasiswa Fakultas Kedokteran Universitas Udayana tergolong tinggi, sedangkan pada tingkat kecenderungan dalam melakukan Social loafing tergolong dalam kategori sangat rendah.

Berdasarkan penelitian yang telah dilakukan, beberapa saran yang dapat diberikan kepada responden penelitian, yaitu mahasiswa adalah mempertahankan hubungan dengan sesama anggota kelompok melalui komunikasi interpersonal dan perilaku altruisme terutama saat melakukan diskusi kelompok, serta mempertahankan keaktifan dalam proses diskusi kelompok, karena diskusi kelompok merupakan salah satu media yang dapat mengasah kemampuan interpersonal dan mempertajam clinical/soft skill mahasiswa. Beberapa saran juga diberikan pada penelitian selanjutnya, seperti memperluas sampel penelitian pada Program Studi atau Fakultas yang menggunakan sistem block dan menerapkan SGD sebagai metode pembelajaran, serta melakukan penelitian mengenai Social loafing dengan faktorfaktor diluar faktor yang sudah diteliti dalam penelitian ini, karena masih terdapat $82.4 \%$ lain yang dapat memengaruhi Social loafing.

\section{DAFTAR PUSTAKA}

Alnuami, O. A., Jr, L. P., \& M. Maruping, L. (2010). Team Size Dispersion, and Social loafingin Technology-Supported Teams:A Perspective on the Theory ofmoral Disengagement. Journal of Management Information Systems / Summer 27(1), 203-230.

Amin, Z., \& Eng, K. H. (2003). Basics in medical education. Singapore: World Scientific Publishing.

Anggraeni, F., \& Alfian, I. N. (2015). Hubungan kohesivitas dan Social loafing dalam pengerjaan tugas berkelompok pada mahasiswa psikologi universitas airlangga. Jurnal Psikologi Kepribadian dan Sosial, 4(2), 81-87.

Chidambaram, L \& Tung, L.L. (2005). Is out of sight, out of mind? An empirical study of Social loafing in technologysupported groups. Journal Information System Research, 16(2), 149-168, DOI:10.1287/isre1050.0051. 


\section{P. Y. S. PRATAMA DAN N. M. S. WULANYANI}

Davis, J., Millburn, P., T.Murphy, \& M.Woodhouse. (1992). Successful team building: How to create teams that really work . London: Kogan Page.

DeVito, J. A. (2011). Komunikasi antarmanusia. Pamulang: Karisma Publishing Group.

Dikti, D. (2004). Tanya jawab seputar unit dan proses pembelajaran di perguruan tinggi. Jakarta: Departemen Pendidikan Nasional.

Earley, C. P. (1989). Social loafing and collectivism: A comparison of the united states and the people's Republic of China. Administrative Science Quarterly, 34(4), 565-581.

Faturochman. (2009). Pengantar psikologi sosial. Yogyakarta: Pustaka.

Field, A. (2009). Discovering statistic using SPSS 3rd edition. SAGE Publication.

Ghozali, I. (2016). Aplikasi analisis multivariate dengan program IBM SPSS 23. Semarang: Badan Penerbit Universitas Diponegoro.

Hall, D., \& S.Buzwell. (2012). The problem of free-riding in group projects: Looking beyond Social loafing as reason for noncontribution . Active Learning in Higher Education, 14(1), $37-49$.

Hapsari, N. S., \& Yonata, B. (2014). Keterampilan kerjasama saat diskusi kelompok siswa kelas pada materi asam basa melalui penerapan model pembelajaran kooperatif di SMA Kemala Bhayangkari 1 Surabaya. Unesa Journal of Chemical Education,3(2), 181-188.

Harris, T. E., \& Sherblom, J. C. (2008). Small group and team communication. United States of America: Pearson Education.

Harsono. (2008). Student centered learning di perguruan tinggi. Jurnal Pendidikan Kedokteran dan Profesi Kesehatan Indonesia, 3(1), 4-8.

Karau, S. J., \& Williams, K. D. (1993). Social loafing: A metaanalytic review and theoretical integration. Journal of Personality and Social Psychology, 65(4), 681-706.

Kurdi, F. N. (2009). Penerapan student centered learning dan teacher centered learning mata ajar ilmu kesehatan pada Program Studi Penjaskes. Forum Kependidikan, 28(2), 108-113.

Liansyah, T. M. (2015). Problem based learning sebagai metode perkuliahan kedokteran yang efektif. Pedagogik, 8(1), 5563.

Machemer, P. (2007). Student perception of active learning in a large cross-disciplinary classroom. Active Learning in Higher Education (pp. 9-30).

Markus, H. R., \& Kitayama, S. (1991). Culture and the Self: Implications for cognition, emotion, and motivation. Psychological Review, 98(1), 224-253.

Melyana, E. (2013, Oktober 02). Kompasiana. Retrieved Januari 15, 2017, from Kompasiana: http://www.kompasiana.com/ekaimel-melyana/konsep-scl_55281b7df17e61f6188b45ca

Myers, D. G. (2003). Social psychology 8th Ed. New York: McGraw Hill.

Nashori, F. (2008). Psikologi sosial islami. Bandung: PT. Refika Aditama.

Pratama, Y. S. (2015). Studi pendahuluan: Jumlah anggota kelompok dan Social loafing di FK Unud. Denpasar: Tidak dipublikasikan.
Pratama, Y. S. (2017). Isu Social loafing di FK UWK. Denpasar: Tidak dipublikasikan.

Rakhmat, J. (2015). Psikologi komunikasi. Bandung: PT. Remaja Rosdakarya.

Robins, S. R., \& Judge, T. A. (2013). Organizational behavior 15th Edition. United States: Pearson.

Rutkowski, G. K., Cruder, C. L., \& Romer, D. (1983). Group cohesiveness, social norms, and bystander intervention. Journal of Personality and Social Psychology, 44(3), 545552.

Sarwono, S. W., \& Meinarno, E. A. (2009). Psikologi sosial. Jakarta: Salemba Humanika.

Shaw, M. E. (1981). Group Dynamics The psychology of small group behavior 3rd edition. United States of America: McGrawHill Book Company.

Stott, K., \& A.Walker. (1995). Teams teamwork \& teambuilding. Singapore: Prentice Hall.

Sugiyono. (2013b). Statistika untuk penelitian. Bandung: Alfabeta.

Sujarwo, D. (2013). Pengaruh metode pembelajaran dan gaya belajar terhadap hasil belajar. Medan: Penelitian tidak dipublikasikan.

Wildanto, E. (2016). Social loafing pada anggota organisasi mahasiswa Fakultas Psikologi UMS. (Skripsi Tidak Dipublikasikan). Surakarta: Fakultas Psikologi Universitas Muhammadiyah .

Wulansari, H., Hardjajani, T., \& Nugroho, A. A. (2013). Hubungan antara komunikasi yang efektif dan harga diri dengan kohesivitas kelompok pada Pasukan Suporter Solo Sejati (Pasoepati). Jurnal Ilmiah Psikologi Candrajiwa, 1(4), 1-13. 